\title{
Os Fïlmes Cinematográficos e o Serviço Público
}

O RICO SETOR DE FILMES

\section{Rachel Marshall Goetz \\ Tradução de Sylvio do Valle Amaral}

amador audiovisual está, possìvelmente, se divertindo com a idéia da produção de dispositivo ou mesmo de filme cinematográfico. Nenhum dêsses, porém, está ao seu alcance, devido à circunstância de os gastos serem substanciais, mas também porque êsse último meio tem potencialidades que, provàvelmente, o iludirão. Pode, entretanto, encontrar no campo das películas já existentes, inimagináveis recursos, tanto para o treinamento em serviço, como para os programas de informação pública.

O QUE OS FILMES PODEM CONSEGUIR E NÃO CONSEGUIR

Os filmes cinematográficos podem, como nenhum outro auxílio visual, desempenhar algumas tarefas. Possuem vigor de impossivel rivalidade quanto aos demais meios; potencialmente movimentondições de mostrar atitudes e fatos. As qualidades de podem ter emprếg e progresso ligadas a uma história dramática os personagens exibido modo que o observador se identifica com despertar as emocôós h. Esse fato é poderosa alavanca para despertar as emoçöes humanas e obter ação.

\section{FILMES CINEMATOGRÁFICOS}

Usualmente bem recebidos, sempre atraem o espirito.

* Criam clima favorável ao aprendizado. contada.

Mantêm atenção até que a história completa seja

* Atingem as pessoas em grupos. sucessivos.

Podem ser usados freqüentemente com grupos
vos. 
* Podem ser repetidos sempre que isso apresente eficiência.

* Podem ser destinados a realizar tarefa especial com grande vantagem.

* Podem dar nôvo significado ao lugar-comum.

* Podem condensar tempo e distância.

* Podem, como outros visuais, sobrepujar muitas diferenças, que dividem os homens e dificultam outras formas de comunicação.

A despeito dessas vantagens, há ocasiões em que os filmes cinematográficos não funcionam tão bem como alguns dos outros artifícios, mais baratos. Uma pelicula é produto acondicionado, de flexibilidade rigorosamente limitada. Despertará, às vêzes, interêsse, mas é dificil incluí-la em discussão posterior sem que desapareça a espontaneidade do grupo.

Nenhum filme desempenha auto-ensinamento, embora muitos professôres gostem de pensar o contrário. Não pode explorar a vantagem de uma situação didática, de modo que muita da respectiva eficiência desaparecerá, caso não seguida por explicação, debate e aplicação.

Assim, embora o filme possa introduzir, reforçar e suplementar quanto o professor tem a dizer, não pode substitui-lo.

Os filmes, além disso, tendem a associar-se com recreação, circunstância que, às vêzes, apresenta real perigo didático.

A despeito dessas ressalvas, um filme apropriado é ainda recurso primordial de ensino. Quantos pretendam conseguir o máximo dos auxílios visuais farão bem procurar uma pelicula cinematográfica, que sirva ao propósito em vista.

O servidor público que puder encontrar caminho através da massa de
Produtores de filmes
Filmotecas de aluguel
Listas de peliculas e
Serviços de avaliação

controlará muitas centenas de filmes, cada um dos quais terá custado a alguém dezenas de milhares de dólares. É objetivo dêste e do capitulo seguinte iluminar o caminho pelo interior dessa-luxuriante vastidão.

\section{FILMES GOVERNAMENTAIS}

O funcionário oficial à procura de filmes utilizáveis desejará saber quais as outras jurisdições do govêrno produtoras de filmes, que lhe sejam unteis. 


\section{ABUNDÂNCIA DE MEIOS QUANTO AOS FILMES GOVERNAMENTAIS}

O volume de peliculas produzido ou patrocinado pelo govêrno, muito grande, está em contínuo desenvolvimento. O govêrno federal realizou mais de 7.000 peliculas; quase todos departamentos estão ligados ao trabalho fílmico. O "Department of Defense" tem sido o principal produtor de filmes de treinamento. O "State Department", bem como as entidades de assistência técnica estão, ainda, produzindo continuamente peliculas, que interpretam a politica americana interna e externa. O "Department of Agriculture" e - "Department of the Interior", notàvelmente o "Bureau of Mines" e o "Bureau of Public Roads" são produtores de primeira-linha. O "Communicable Disease Center of the Public Health Service" consegue mais de quarenta peliculas cinematográficas anualmente e também igual número de diafilmes. Outros ramos do "Department of Health, Education and Welfare" (antes, "Federal Security Agency") isto é, o "Office of Education" o "Children's Bureau" e o "Food and Drug Administration", tratam igualmente do assunto. "O Federal Bureau of Investigation" usa substancial número de filmes para treinamento policial.

Os governos estaduais geralmente, e não poucas vêzes os locais, também produzem certo volume de películas. Aproximadamente metade dos departamentos estaduais de saúde têm rodado seus próprios filmes; os departamentos estaduais de bem-estar e de rodovias estão, por sua vez, grandemente interessados em produzir ou patrocinar filmes. Cada Estado na União dirige, usualmente por meio do seu programa de extensão universitária, uma filmoteca de aluguel, pelo menos. Em conjunto, há 271 dessas filmotecas operadas pelo Estado, as quais totalizam 130.000 rolos de películas.

Os governos citadinos, igualmente, descobriram filmes; algumas cidades fazem quanto é possivel a respeito. Pesquisa em 32 localidades revelou 512 filmes em uso e dêles, um quarto, aproximadamente, foi, de fato, produzido pelas próprias cidades. O material sôbre segurança de tráfego tèm primazia.

Muitos dêsses filmes, em todos os niveis qovernamentais, merecem ainda uso mais amplo. Embora elaborados nara determinada localidade, podem, amiúde, ser usados com efeitos muito semelhantes em quaisquer lugares. Mesmo quando não inteiramente transplantados constituem lições úteis para outras zonas.

\section{COMPENSA OBTÊ-LOS POR EMPRÉSTIMO}

Além das fontes no campo governamental, existe potencial ainda não usado no terreno industrial e educativo. 
Os filmes são feitos segundo a existência americana e há milhares de novos títulos produzidos anualmente. O número de filmes realizado com obejtivos outros, mas agora utilizável pelo govêrno, é muito alto. Uma lista de peliculas destinadas a treinamento, digamos, inclui cêrca de 3.000 títulos, enquanto que as referências padronizadas no setor educacional não superiores a 8.000 . Riquezas ainda não trabalhadas quanto a filmes de treinamento em campos tais como direção de escritório, supervisão, práticas pessoais, relações públicas e relações humanas, oferecem compensadora exploração. Há também, literalmente, milhares de filmes de uso potencial em programas de informação.

Melhoramentos técnicos estão agora num caminho que promete tornar mais úteis os filmes já existentes. Os projetores sonoros de $16 \mathrm{~mm}$, que estão aparecendo no mercado, podem passar - filme com pista sonora magnética (a exemplo do gravador de fita), ao invés da ótica. Tornando, assim, possível gravar novamente o som para adaptar-se a propósitos diferentes daqueles para os quais originàriamente pretendidos, ditas máquinas aumentarão sobremaneira a utilidade de numerosíssimos filmes cinematográficos.

O significado para o treinamento, quanto ao serviço público, dessas realizações, é difícil ser subestimado.

Os filmes produzidos, de início, para a indústria, agora já podem ser, de nôvo, fàcilmente editados e transplantados com apropriado comentário para o serviço público.

Muitos dos clientes, em perspectiva, dos filmes cinematográficos, ficam coibidos pela idéia das imensas dificuldades que apresenta o encontro de filmes, tela, projetor e operador. As barreiras são menos proibitivas do que, à primeira vista, parecem. Eis o modo de sobrepujárlas.

\section{COMO ENCONTRAR FILME CONVENIENTE}

De início, procure assistência do mais próximo Centro de Informação de Filmes.

Nos Estados Unidos da América do Norte há mais de 1.000 dessas instituições, cujo nome varia: comissöes de filmes e serviços audiovisuais, não só de filmotecas públicas, mas também de universidades estaduais.

Verifique ainda as filmotecas locais, de aluguel. Um exemplar do "A Directory of $2.00016 \mathrm{~mm}$ Film Libraries" ("Federal Security Agency", Boletim 1951, n" 11) se consegue do "Government Printing Office", Washington 25, D.C., por 30 centésimos de dólar. 
A obra padrão para referência sôbre filmes, encontrável na maior parte das bibliotecas públicas, é o Educational Film Guide, que vem à estampa, anualmente, com suplementos trimestrais, graças a H. W. Wilson Company, 950 Un.versity Avenue, New York, 52, New York (US\$ 5.00). A Biblioteca do Congresso está presentemente ocupada no trabalho de produzir fichas relativas a películas disponiveis. Abrangerá as feitas desde $1^{\circ}$ de janeiro de 1952, sejam do govêrno, também as sob copirraite e ainda as que produtores particulares desejam ver incluidas. Quatro mil cartões serão distribuidos durante êste ano. Examine sua biblioteca.

Caso seu orçamento seja tão reduzido que impeça muitos aluguéis (poucos filmes educacionais são alugados por mais de US $\$ 5.00$ cada exibição) lance mão dos emprestados gratuitamente. Nesse caso tente o Educator Guide to Free Films, publi cado pelo "Educator Press Service", Randolph, Wisconsin. Esse guia freqüentemente existe em bibliotecas públicas ou pode ser adquirido por US\$ 6.00 .

Se você quiser saber quais os filmes do govêrno norte-americann disponiveis, há uma publicação, 3434 UI.S. Government Films, compilado pelo "U.S. Office of Education" ("Federal Security Agency", Boletim 1951, n' 21), conseguivel graças ao "Government Printing Office", Washington 25, D.C., por 70 centésimos de dólar. Os filmes estâo relacionados alfabèticamente apenas sob título.

Muitas relações de películas são pouco satisfatórias, eis que não fornecem lugares onde são alugadas ou avaliações úteis aos funcionarios públicos. Há oportunidades de que pesquisas em bibliografias de grupos profissionais.e associações comerciais mostrem filmes extremamente uteis para servidores governamentais. filmes:

Três organizações oficiais produzem suas próprias listas de

A Select List of Films for Public Employee Training. Civil Service Assembly, 1313 East 60th Street, Chicago, 37, Illinois, 1953 (US\$ 2.00).

Motion Picture Film on Planning and Housing: A Bibliography. American Society of Planning Officials, 1313 East 60th Street, Chicago 37, Illinois, 1951 (US $\$ 0.50$ ).

Films in Public Works. American Public Works Association, 1313 East 60th Street, Chicago, 37, Illinois, 1952. (Dirigir-se a seção local para inspecionar a série, que arbange 200 filmes distribuidos em 20 categorias, inclusive boa administração pública, fornecimento e purificação dágua, cuidado e manutenção de ve1culos, materiais e respectivo manejo. 

úteis:

Eis algumas outras listas de filmes especializados, que são Defesa Civil

U.S. Civil Defense Official Film Listing. Federal Civil Defense Administration, Washington 25, D.C.

Sixteen Millimeter Films of Britain at War. British Information Service, 30 Rockefeller Plaza, New York 20, New York.

Democracia e Herança Americana

One Hundred Two Films on Democracy. Office of Education, Department of Health, Education and Welfare, Washington 25, D.C., 20.

The American Heritage in Films. American Library Associa tion, 50 East Huron Street, Chicago 11, Illinois.

Bibliography of Films for the Orientation of Immigrants, American Library Association, 50 East Huron Street, Chicago 11. Illinois.

Citizenship Movies. National Education Association, 1201 16th St. N.W. Washington, D.C.

Prevenção de Incêndios e Treinamento de Bombeiros

Fire Control List. National Fire Protection Association, 60 Batterymarch Street, Boston, Massachusetts.

Fire Prevention Films. National Board of Fire Underwiters Film Library, Bureau of Communications Research, Inc. 13 East 37th Street, New York 17, New York

Saúde, Saúde Mental e Bem-Estar

Motion Pictures on Child Life. Children's Bureau, Department of Health, Education, and Welfare, Washington 25, D.C.

Mental Health Motion Pictures. Public Health Service $\mathrm{Pu}$ blication $n^{\circ}$ 218, Superintendent of Documents, Government Printing Office, Washington 25, D.C.

Psychological Cinema Register. Pennsylvania State Colege, Pennsylvania.

Audio-Visual Resources for Health and Welfare. See and Hear Magazine, 7064 N. Sheridan Road, Chicago, Illinois.

Child Development. New York University Film Library, Press Annex Building, 26 Washington Place, New York 3, New York.

Films on Emotional Health, Child Development, Education and Health. Columbia University, Communications Materials Center, 413 West 117th St., New York 27, New York. 
Films on Mental Health. International Film Bureau, $6 \mathrm{~N}$. Michigan Avenue, Chicago 2, Illinois.

Health and Welfare Films and Film Strips. National Film Board of Canada, 400 W. Madison Street, Chicago 6, Ilinois.

Selected Films for Hospital Administration. State University of Iowa, Iowa City, Iowa.

Films Made by Community Chests and Councils of Social Agencies. Community Chests and Councils, Inc., 155 East 44th Street, New York, New York.

Moradia e Planejamento

Films on Housing. Public Housing Administration, Housing and Home Finance Agency, Washington 25, D.C., November, 1950.

Relações Humanas

Human Relations on the Screen. EFLA Service Supplement, Educational Film Library Association, 1600 Broadway, New York 16, New York.

Films and Filmstrips Available from Anti-Defamation League, B'Nai Brith, 327 S. La Salle Street, Chicago 4, Illinois, grátis.

Films on Intergroup and Community Relations. University of Illinois. Champaign, Illinois.

Delinqüência Iuvenil

Fim Catalogue. N.Y. State Youth Comission, 40 Howard Street, Albany 7, New York.

Suggested Film Bibliography for Police-Juvenile Officers. Delinquency Control Institute, University of Southern California, Los Angeles, Attention: Dr. John Gerletti, mimeografado.

Treinamento Policial

Films for Police Training. Pennsylvania State College, State College, Pennsylvania, mimeografado.

Police Training Films. Federal Bureau of Investigation (dis ponivel sòmente para policiais). Escrever para o escritório local desta instituição ou para Mr. J. Edgar Hoover, FBI, U.S. Department of Justice, Washington, D.C.

Training Films. California State Department of Education, Peace Officers'Training Division, Sacramento 14 , California, mi-
meografado.

Segurança

National Directory of Safety Films. National Safety Council, 20 N. Wacker Drive, Chicago 6, Illinois, 25c 
One-Minute Traffic Safety Films. National Safety Council, 20 N. Wacker Drive, Chicago 6, Illinois.

Supervisão, Treinamento e Direção

Film Guide on Industrial Relations. Film Research Associates, 135 W. 52nd Street, New York, 19, New York, \$3.00.

Film Guide for Improving Office Practices. Film Research Associates, \$1.50.

Film Guide on Production and Management Methods. Film Research Associates, \$1.50.

Index of Training Films. Business Screen Magazine, 7064 N. Sheridan Road, Chicago, Illinois, \$2.00.

Motion and Time Study Films. State University of Iowa Industrial Engineering Film Library, Iowa City, Iowa.

Supervision: Key to Manpower Utilization, United World Films, 1445 Park Avenue, New York 29, New York.

A Guide to Audio-Visual Materials in Manpower and Industrial and Labor Relations. New York State School of Industrial and Labor Relations, Cornell University, Ithaca, New York, 25c.

Films and Filmstrips for Labor Groups. Institute of Management and Labor Relations, Rutgers University, New Brunswick, New Jersey.

Listas das Nações Ulnidas

United Nations Films. Department of Public Information, United Nations, 610 Fifth Avenue, New York 20, New York.

Child Welfare Films. UNESCO and WHO, Films and Visual Information Division, Department of Mass Communications, UNESCO, 19 Avenue Kleber, Paris 16, France, \$1.00.

\section{Auxiltos Visuais}

Suggested Visual Aids for Use in the Teaching of AudioVisual Aids. Pennsylvania State College, State College, Pannsylvania, mimeografado.

Miscelânea

A Library of Educational and Instructional Sports Films. A. G. Spalding and Brothers, 161 Sixth Avenue, New York 13, New York, grátis.

\section{RESERVE OS FILMES COM ANTECEDÊNCIA}

Com antecedência até de meses, quando possivel, reserve e obtenha confirmação das respectivas datas. Devolva-os prontamente. Não esqueça de garanti-los pelo seguro; as cópias são de preço alto. 


\section{A LOCALIZAÇÃO DA TELA E DO PROJETOR}

A maior parte das casas fornecedoras e vendedoras de equipamento alugam telas $\left({ }^{*}\right)$. Poderse consegui-las por US $\$ 1.50$ e mais, diàriamente. Grande número de hotéis, escolas e igrejas já as possuem. As chamadas telas à luz do dia prescindem escurecimento completo. Se não houver disponibilidade de tela, use parede, preferivelmente branca. Exibições a céu aberto, com sucesso, podem ser conseguidas graças a projeção contra muro pintado dessa côr.

Telas enroláveis apresentam maiores vantagens à instalação permanente, porém, as com pés têm flexibilidade superior àquelas.

Uma tela de 70 polegadas quadradas $(1,75 \mathrm{~m} 2)$ é mais útil em salas de aulas, eis que serve para filmes cinematográficos e diafilmes. A distância do projetor à tela controla o tamanho da imagem.

Sempre verifique a bitola do filme. As peliculas educativas são de $16 \mathrm{~mm}$, sonoras; as destinadas às salas de projeção comercial, de $35 \mathrm{~mm}$.

Não tente passar filme sonoro em projetor silencioso. Caso se faça isso, a película ficará perfurada. A silenciosa pode ser exibida em máquina sonora.

Você talvez possa alugar um projetor. Muitas igrejas e clubes de serviços agora possuem tais máquinas. Numerosas casas fornecedoras de materiais fotográficos e vendedores de audiovisuais não só os alugam e vendem, mas também o ensinam a trabalhar. com êles. Os sonoros são aluqáveis pnr uns US\$ 15.00 diários. A revista Business Screen, 7064 Sheridan Road, Chicago, I1linois, Estados Unidos da América do Norte, publicou um manual de equipamento audiovisual, preço US $\$ 3.50$

\section{COMO ARRANJAR UM PROJECIONISTA}

Em muitas cidades, a "Motion Pictures Operators Union" fornecerá um operador e equipamento por US\$25 cada sessão. As escolas e os cine-clubes locais podem, normalmente, indicar projecionistas amadores. (Examine os regulamentos dos sindica-
tos).

Aprenda por si mesmo a trabalhar com projetor - você ficará sabendo em uma hora com auxílio de bom manual sôbre o assunto.

(*) A «National Audio-Visual Association», 2540 East Wood Avenue Evanston, Illinois, fornecerá lista de alcance nacional quanto a seus elementos. Também publica o Current Models of Audio-Visual Equipment, 1953, US\$ 3.00. 
Dois dêles são:

The ABC's of Visual Aids and Projectionist's Manual, por Philip Mannino. Disponivel em M.O. Publishers, Box 406, State College, Pennsylvania, US\$ 1.00 .

The Projectionist's Handbook. Business Screen, 7064 Sheridan Road, Chicago, 26 Illinois, US $\$ 1.00$.

\section{PRODUZIR E NÃO PRODUZIR}

A produção de filmes cinematográficos é tão dispendiosa que se torna impossivel, exceto para os grandes orçamentos. As estimativas profissionais sobem a mais de US $\$ 1.000$ por minuto de exibição, no caso de películas sonoras coloridas.

Os filmes amadores são fativeis, mas aqui e ali sofrem relativamente às produções profissionais. Há, entretanto, ocasiões $\mathrm{cm}$ que produções oficiais "feitas em casa" servem muito bem a objetivo modesto. Número cada vez maior de cidades, inclusive Eugene, Oregon e San Mateo, na Califórnia, têm usado essas películas, a fim de relatar serviços governamentais aos cidadãos do local. Julgam que com imaginação, cuidadoso planejamento e trabalho pesado de voluntários devotados, consegue-se produzir uma película útil por uns US $\$ 1.000$.

Essas produções "domésticas" se tornarão mais fáceis futuramente. A técnica cinematográfica está em rápida expansão. Crescente número de universidades e de outras organizações não comerciais vem produzindo filmes a preço de custo. As universidades, ainda, ensinam cinematografia. A "University of Southern California" e a "Indiana University" estão experimentando cursos intensivos e rápidos, que vão aumentar o número de amadores. Claro, o processo da produção cinematográfica é muito técnico e o equipamento necessário por demais custoso para merecer estudo detalhado neste manual de "como fazer".

Caso se esteja a pensar em filme profissional - o número dêles está em rápido crescimento - convirá ficar em dia com o artigo "A Buyer's Guide to Qualified Film Producers", na revista Business Screen, volume 14, $\mathrm{n}^{\circ} 1,1963$.

("Visual aids for the public service, por Rachel Marshall Goetz, Chicago, Public Administration Service, 1954, capitulo V, páginas 57 a 72 ). 